\title{
The prognosis of primary intracerebral tumours presenting with epilepsy: the outcome of medical and surgical management
}

\author{
D F Smith, J L Hutton, D Sandemann, P M Foy, M D M Shaw, I R Williams, \\ D W Chadwick
}

\begin{abstract}
It is not known whether conservative or early aggressive (resective surgery with or without radiotherapy) management is better for tumours presenting with epilepsy. The prognosis of 560 patients with a clinical and CT diagnosis of intrinsic supratentorial tumour was examined retrospectively. Epilepsy was the first symptom in 164 patients. Histological confirmation of diagnosis was available in $391(70 \%)$ of cases. Median survival was 37 months in the group presenting with epilepsy and six months in those presenting with other symptoms (p $<0.0001)$. Patients presenting with epilepsy were more likely to have a normal clinical examination, a non-enhancing low density lesion on CT scan and a low grade tumour. From Cox's stepwise proportional hazards model, significant independent variables adversely affecting prognosis were increasing age, focal neurological signs and enhancing $C T$ lesions at diagnosis, non-resective surgery and male sex. Of those presenting with epilepsy 80 patients had surgical treatment within two months of CT diagnosis. The Cox's model failed to identify any beneficial effects for either early resective surgery or radiotherapy. In primary intracerebral tumours with presentations other than epilepsy, resective surgery and radiotherapy were amongst the important factors associated with prolonged survival. Primary intracerebral tumours presenting with epilepsy are relatively benign and their outcome appears to be chiefly determined by clinical factors.
\end{abstract}

Controversy exists regarding the management of intrinsic brain tumours. ${ }^{1}$ Neurologists believe that resective surgery and radiotherapy are essentially palliative and carry some risks. ${ }^{2}$ They accept that radiotherapy prolongs survival in malignant gliomas ${ }^{3-5}$ but feel that quality of life may be poor ${ }^{67}$ and that evidence for the benefit of resective surgery is unconvincing and derived from work on selected populations. ${ }^{89}$ Neurosurgeons are more positive about the benefits of radiotherapy and extensive surgical resection in both high ${ }^{10-13}$ and low-grade tumours. ${ }^{1415}$ They express the concern that conservative management may lead to misdiagnosis and delayed treatment of potentially curable conditions.
The clinical dilemma is greatest for less malignant tumours. Neurologists often investigate patients with epilepsy and find low density mass lesions on a CT scan. They manage such patients conservatively by treating their seizures and clinical experience suggests that many patients will survive for years with epilepsy as their only symptom.

Information, derived from surgical series, has suggested that patients presenting with epilepsy have a relatively good prognosis ${ }^{13} 1617$ and this may be irrespective of tumour grade. ${ }^{17}$ Several recent studies have demonstrated that, in patients with intrinsic supratentorial tumours, the most important clinical predictors of outcome are age $\mathrm{5}^{518}$ and performance status at presentation. ${ }^{51620}$ Tumour grade has been shown to be an important prognostic factor in some series ${ }^{19}{ }^{21}$ but not in others. ${ }^{1314}$ The widespread and increasing availability of sensitive neuro-imaging techniques (CT and MRI) means that patients with a short history of epilepsy are more likely to be scanned. A proportion of these will be shown to have "lesions" which are probably gliomas. This is therefore an increasingly common management problem for both neurologists and neurosurgeons and neither group knows whether the optimal management approach is early surgery and radiotherapy or a conservative policy of symptomatic treatment until other problems develop.

A retrospective analysis of the prognosis of patients with a diagnosis, on clinical and CT grounds, of primary intrinsic supratentorial tumour has been conducted.

\section{Methods}

Using the Regional Health Authority records, details of patients classified as ICD code 191: "malignant neoplasm of brain" had previously been recorded on two databases. The first ${ }^{1}$ contained details of patients presenting to two consultant neurologists (DWC, IRW) and two consultant neurosurgeons (MDMS, PMF) between 1978 and 1982 and the second ${ }^{8}$ details of patients presenting to the department between January 1983 and June 1986. All patients with infratentorial lesions were excluded. To these two databases, containing details of patients with all presentations of intrinsic supratentorial tumours, was added a third database of patients whose first symptom was epilepsy. These latter patients had presented to neurologists in the department between 1975 and September 1989. 
The case records of all patients presenting with epilepsy were reviewed. Information was collected on presenting symptom, clinical findings including conscious level at presentation, EEG findings, CT features at diagnosis, the effectiveness and complications of several treatments (anticonvulsant therapy, steroid, surgery and radiotherapy) and outcome. The duration from first symptom to presentation, to CT diagnosis and to surgical treatment were recorded. If more than one operation was performed the time to most definitive procedure was recorded. The time of diagnosis was taken as that of the first CT scan interpreted as showing a tumour and survival was calculated from that date to death or final follow up. The CT scans of patients were reviewed by a consultant neuroradiologist. The appearances of the lesion were reported according to the presence or absence of the following features: diffuse low density, cystic change, shift, calcification and contrast enhancement.

Histology was taken directly from pathological reports in case notes. For the purposes of this study Kernohan grades I and II were considered to be "low grade", Kernohan grades III, IV and malignant glioma were "high grade" and glioblastoma multiforme was recorded separately.

For purposes of analysis the study was completed on 19 February 1990 and follow up information was available in all patients. Date of death was obtained either from case records or from the local cancer registry. For those patients still alive the date of final follow up was obtained from case records or by directly contacting patients. There were 37 patients, presumed to be alive, who were not contactable within three months of the date for analysis. Only seven of these had no follow up information in 1989.

The group was divided into those whose first symptom was epilepsy and those whose first symptom was not epilepsy. The two groups were compared in terms of clinical and CT features at diagnosis, treatment modalities, histology, grade and outcome.

The group presenting with epilepsy were subdivided into those who had early surgery (within two months of CT diagnosis) and the rest. This latter group included patients who had surgery at a later date and patients not operated on at any time. The reason for this division was to avoid unfair bias against surgical treatment as in some patients the initial decision was to treat conservatively but this was reconsidered after neurological deterioration. These two groups (early surgery, no early surgery) were compared for clinical and CT features at presentation and outcome.

Confidence intervals for odds ratios were calculated using Confidence Intervals Analysis. ${ }^{22}$ Initial comparison of the survival of the two groups used the Kaplan-Meier product limit estimate. Cox's proportional hazards model $^{23}$ was used to investigate the effect of covariates on survival. The covariates are the main symptoms at presentation, results from CT scans and treatment variables. As there were 93 deaths in the group presenting with epilepsy and 372 in the group presenting with other symptoms, it was reasonable to consider several explanatory variables.

\section{Results}

A) Comparison of patients presenting with epilepsy and those presenting with other symptoms

A total of 560 patients were identified of whom 164 had epilepsy as their first symptom and 396 presented with other symptoms.

The group presenting with epilepsy was younger (mean age 45 years, range six to 76 years) with a preponderance of males $(M: F=$ 109:55). Patients with other presentations were older (mean age 55 years, range six to 80 years) with a more even sex distribution (M:F = 219:177). Average duration of symptoms before CT diagnosis was 28 months (range two days-232 months) in those presenting with epilepsy and four months (range one day-175 months) in those with other presentations.

In those presenting with epilepsy seizures were refractory to anti-epileptic drugs with only $11 / 164$ patients ever achieving a one year remission. EEG was performed at diagnosis in $102 / 164$ patients. This showed no abnormality in nine, non-specific abnormality in 13 , focal spikes in six, focal spike and slow wave in six and focal slow wave abnormalities only in 68 .

One hundred and seven of one hundred and sixty four patients $(65 \%)$ presenting with epilepsy and $284 / 396(71 \%)$ with other presentations had some form of surgery with resective surgery being performed in $32(20 \%)$ and 43 $(11 \%)$ cases respectively. Eighty six $(52 \%)$ of those presenting with epilepsy and $250(63 \%)$ of the rest had radiotherapy. The diagnosis of glioma was histologically confirmed in 100 $(61 \%)$ patients presenting with epilepsy and $256(65 \%)$ of the other group.

In the group presenting with epilepsy 80 patients had "early" surgery (within two months of CT diagnosis), 27 had "delayed" surgery (more than two months after CT diagnosis) and 57 had no surgery.

Odds ratios were used to determine whether there were any significant differences between the two groups (epilepsy as first symptom and other presentations). Table 1 shows the odds ratios for a variety of clinical, CT, treatment, histology, grade and outcome variables.

Patients presenting with epilepsy were significantly more likely to be male, have no neurological symptoms or signs and to have a non-enhancing low density or calcified lesion on CT scan. They are possibly more likely to have an oligodendroglioma although this histology was rare in the group as a whole $(n=15)$. They appear more likely to have low grade tumours but this may be misleading for three main reasons. Firstly, no histology was available in $57 / 164(35 \%)$ and $112 / 396(28 \%)$ cases respectively. Secondly, uninformative histology was obtained in seven $(4 \%)$ and $28(7 \%)$ of cases operated on. Thirdly, in 46/164 (28\%) and 93/ $396(23 \%)$ cases whilst the diagnosis was confirmed the tumour grade was not specified. Patients presenting with epilepsy were less 
Table 1 Odds ratios for the frequency of different variables in patients with cerebral tumours (whole study population)

\begin{tabular}{|c|c|c|c|}
\hline & $\begin{array}{l}\text { First symptom } \\
\text { epilepsy }\end{array}$ & $\begin{array}{l}\text { First symptom } \\
\text { not epilepsy }\end{array}$ & $\begin{array}{l}\text { Odds ratios } \\
95 \% \text { confidence limits }\end{array}$ \\
\hline Total number & $\begin{array}{l}164 \\
\% \text { of total in each group } \\
\text { with factor present }\end{array}$ & 396 & \\
\hline $\begin{array}{l}\text { Clinical factors: } \\
\text { Sex }=\mathbf{M}^{\star \star} \\
\text { Focal symptoms } \\
\text { Mental symptoms`}^{\star} \\
\text { Papilloedema }^{\star} \\
\text { Focal signs }^{\star} \\
\text { Mental signs }\end{array}$ & $\begin{array}{r}66 \\
23 \\
8 \\
13 \\
37 \\
12\end{array}$ & $\begin{array}{l}55 \\
69 \\
58 \\
39 \\
77 \\
57\end{array}$ & $\begin{array}{l}1.60(1.10,2.34) \\
0.14(0.09,0.21) \\
0.07(0.04,0.12) \\
0.23(0.14,0.38) \\
0.18(0.12,0.26) \\
0.10(0.06,0.17)\end{array}$ \\
\hline $\begin{array}{l}\text { CT factors: } \\
\text { Low density } \\
\text { Non enhancing low density }{ }^{\star \star} \\
\text { Cyst } \\
\text { Shift } \\
\text { Calcification } \\
\text { Enhancement } \\
\text { En }\end{array}$ & $\begin{array}{l}60 \\
29 \\
26 \\
76 \\
16 \\
59\end{array}$ & $\begin{array}{r}84 \\
4 \\
25 \\
86 \\
6 \\
89\end{array}$ & $\begin{array}{l}0.28(0.18,0.42) \\
8.65(4.77,15.6) \\
1.08(0.71,1.64) \\
0.51(0.32,0.80) \\
3.06(1.69,5.54) \\
0.12(0.07,0.19)\end{array}$ \\
\hline $\begin{array}{l}\text { Treatment factors: } \\
\text { Radiotherapy } \\
\text { Any surgery } \\
\text { Resective surgery } \\
\text { Non-resective surgery }\end{array}$ & $\begin{array}{l}52 \\
65 \\
20 \\
46\end{array}$ & $\begin{array}{l}63 \\
71 \\
11 \\
61\end{array}$ & $\begin{array}{l}0.66(0.45,0.93) \\
0.74(0.50,1.09) \\
1.99(1.21,3.28) \\
0.54(0.38,0.78)\end{array}$ \\
\hline $\begin{array}{l}\text { Histological factors: } \star \star \star \\
\text { Tumour not confirmed } \\
\text { Astrocytoma } \\
\text { Ependymoma } \\
\text { Oligodendroglioma } \\
\text { Glioma: grade not specified } \\
\text { Other } \\
\text { Glioblastoma }\end{array}$ & $\begin{array}{r}7 \\
50 \\
1 \\
7 \\
7 \\
23 \\
4 \\
9\end{array}$ & $\begin{array}{r}10 \\
59 \\
2 \\
2 \\
19 \\
1 \\
6\end{array}$ & $\begin{array}{l}0.64(0.27,1.51) \\
0.68(0.43,1.06) \\
0.44(0.05,3.67) \\
3 \cdot 20(1.13,9.05) \\
1.33(0.78,2.28) \\
2.72(0.67,11 \cdot 1) \\
1.36(0.59,3 \cdot 12)\end{array}$ \\
\hline $\begin{array}{l}\text { Tumour grade: } \\
\text { Low }{ }^{\star \star} \\
\text { High } \\
\text { Gtioblastoma } \\
\text { Not specified }\end{array}$ & $\begin{array}{r}21 \\
24 \\
9 \\
46\end{array}$ & $\begin{array}{r}11 \\
46 \\
6 \\
36\end{array}$ & $\begin{array}{l}2.16(1.16,4.03) \\
0.38(0.22,0.63) \\
1.31(0.57,3.02) \\
1.49(0.94,2.39)\end{array}$ \\
\hline $\begin{array}{l}\text { Outcome: } \\
\text { Dead } \\
\text { Alive and independent }\end{array}$ & $\begin{array}{l}57 \\
38\end{array}$ & $\begin{array}{r}94 \\
5\end{array}$ & $\begin{array}{c}0.08(0.05,0.14) \\
12.4(7 \cdot 12,21 \cdot 7)\end{array}$ \\
\hline
\end{tabular}

Odds ratios estimate the relative distribution of a variable between two groups. An odds ratio of unity means the variable is equally likely to occur in both groups.

॥If $95 \%$ confidence limits $<1.0$ that variable is significantly $(p<0.05)$ more likely to occur in the group whose first symptom is not epilepsy.

${ }_{\star \star}$ If $95 \%$ confidence limits $>1.0$ that variable is significantly $(p<0.05)$ more likely to occur in the group whose first symptom is

$\star \star \star$ The denominator for histological factors is 107 for those whose first symptom is epilepsy and 284 for the rest.

likely to receive radiotherapy or non-resective (biopsy) surgery but more likely to undergo resective surgery. Patients presenting with epilepsy were less likely to be dead and those who were alive more likely to be independent.

B) Survival in the two groups

The figure shows the Kaplan-Meier survival curve for the two groups. It demonstrates that median survival was 37 months for those whose first symptom was epilepsy and six months for those presenting with other symptoms.

Figure Influence of presentation with epilepsy
on survival experience of on survival experience of
patients with cerebral tumours.

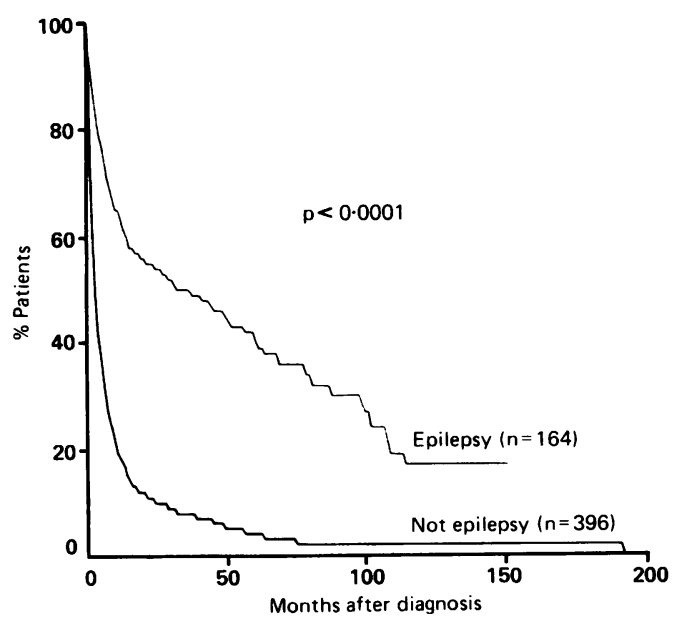

Table 2 Cox's stepwise proportional hazards model. Relative risk of mortality associated with different variables (whole study population)

\begin{tabular}{|c|c|c|c|}
\hline & Beta & $p$ & $\begin{array}{l}\text { Relative risk } \\
\text { (95\% confidence } \\
\text { limits) }\end{array}$ \\
\hline Age & 0.0218 & $<0.0001$ & \\
\hline $\begin{array}{l}\text { First symptom } \\
\text { epilepsy } \\
\text { DXT }\end{array}$ & $\begin{array}{l}-0.7815 \\
-0.7849\end{array}$ & $\begin{array}{l}<0.0001 \\
<0.0001\end{array}$ & $\begin{array}{l}0.46(0.34,0.61) \\
0.46(0.36,0.57)\end{array}$ \\
\hline $\begin{array}{l}\text { Non-resective } \\
\text { surgery } \\
\text { Focal signs }\end{array}$ & $\begin{array}{l}0.5666 \\
0.4483\end{array}$ & $\begin{array}{r}<0.0001 \\
0.0001\end{array}$ & $\begin{array}{l}1.76(1.43,2.17) \\
1.56(1.24,1.97)\end{array}$ \\
\hline $\begin{array}{l}\text { Enhancement } \\
\text { on CT } \\
\text { Cyst on CT }\end{array}$ & $\begin{array}{r}0.3999 \\
-0.2822\end{array}$ & $\begin{array}{l}0.0018 \\
0.0124\end{array}$ & $\begin{array}{l}1.49(1.16,1.92) \\
0.75(0.60,0.94)\end{array}$ \\
\hline
\end{tabular}

C) Factors affecting survival

To determine what factors influence prognosis in the group as a whole ( 560 patients) Cox's stepwise proportional hazards model was used. The importance of these variables is expressed by hazard ratios (or relative risk) of mortality associated with their presence. Table 2 shows the model which demonstrates that age is the most significant independent variable. Since age is a continuous variable a single hazard ratio cannot be given but the risk of mortality is increased by a factor of 1.5 for every decade. Epilepsy as a first symptom was the second most important factor influencing outcome. Further- 
Table 3 Odds ratios for the frequency of different variables in patients with cerebral tumours (first symptom epilepsy only)

\begin{tabular}{|c|c|c|c|}
\hline \multirow[b]{2}{*}{ Total number } & \multicolumn{2}{|c|}{ Early surgery: no early surgery } & \multirow{2}{*}{$\begin{array}{l}\text { Odds ratios } \\
95 \% \text { confidence limits }\end{array}$} \\
\hline & $\begin{array}{l}80 \\
\% \text { of total in each group } \\
\text { with factor present }\end{array}$ & 84 & \\
\hline $\begin{array}{l}\text { Clinical factors: } \\
\text { Male sex } \\
\text { Focal symptoms } \\
\text { Mental symptoms } \\
\text { Papilloedema } \\
\text { Focal signs } \\
\text { Mental signs }\end{array}$ & $\begin{array}{l}65 \\
38 \\
11 \\
20 \\
53 \\
15\end{array}$ & $\begin{array}{r}68 \\
10 \\
6 \\
6 \\
23 \\
10\end{array}$ & $\begin{array}{l}0.88(0.46,1.68) \\
5.70(2.42,13.4) \\
2.00(0.64,6.26) \\
3.95(1.37,11.4) \\
3.78(1.93,7.42) \\
1.68(0.65,4.35)\end{array}$ \\
\hline $\begin{array}{l}\text { CT factors: } \\
\text { Low density } \star \star \\
\text { Non-enhancing low density } \star \\
\text { Cyst } \\
\text { Shift } \\
\text { Calcification } \\
\text { Enhancement }\end{array}$ & $\begin{array}{l}51 \\
13 \\
33 \\
83 \\
18 \\
76\end{array}$ & $\begin{array}{l}68 \\
44 \\
20 \\
70 \\
14 \\
43\end{array}$ & $\begin{array}{l}0.50(0.26,0.94) \\
0.18(0.08,0.40) \\
1.90(0.93,3.85) \\
2.00(0.95,4.20) \\
1.27(0.55,2.95) \\
4.28(2 \cdot 19,8.38)\end{array}$ \\
\hline $\begin{array}{l}\text { Outcome: } \\
\text { Dead }\end{array}$ & 73 & 42 & $3.69(1.92,7 \cdot 11)$ \\
\hline
\end{tabular}

$\star_{\text {If }} 95 \%$ confidence limits $<1.0$ that variable is significantly $(\mathrm{p}<0.05)$ more likely to occur in the group not receiving early

$\star \star \star$ If $95 \%$ confidence limits $>1.0$ that variable is significantly $(p<0.05)$ more likely to occur in the group receiving early surgery.

Table 4 Cox's stepwise proportional hazards model. Relative risk of mortality associated with different variables (first symptom epilepsy)

\begin{tabular}{llrl}
\hline & Beta & $p$ & $\begin{array}{l}\text { Relative risk } \\
\text { (95\% confidence } \\
\text { limits) }\end{array}$ \\
\hline $\begin{array}{l}\text { Focal signs } \\
\begin{array}{l}\text { Age } \\
\text { Enhancement } \\
\text { on CT }\end{array}\end{array}$ & 1.0972 & $<0.0001$ & $3.0(1.86,4 \cdot 81)$ \\
$\begin{array}{l}\text { Non-resective } \\
\text { surgery }\end{array}$ & 1.0044 & 0.0001 & $2.73(1.65,3.79)$ \\
Sex & 0.8790 & 0.0002 & $2.45(1.52,3.82)$ \\
\hline & 0.4571 & 0.0474 & $1.58(1.01,2.56)$ \\
\hline
\end{tabular}

Table 5 Cox's stepwise proportional hazards model. Relative risk of mortality associated with different variables (first symptom not epilepsy)

\begin{tabular}{|c|c|c|c|}
\hline & Beta & $p$ & $\begin{array}{l}\text { Relative risk } \\
\text { (95\% confidence } \\
\text { limits) }\end{array}$ \\
\hline $\begin{array}{l}\text { DXT } \\
\text { Resection } \\
\text { Age }\end{array}$ & $\begin{array}{r}-0.8909 \\
-0.7266 \\
0.0123\end{array}$ & $\begin{array}{r}<0.0001 \\
0.0006 \\
0.0049\end{array}$ & $\begin{array}{l}0.41(0.32,0.53) \\
0.48(0.32,0.73)\end{array}$ \\
\hline
\end{tabular}

Treatment effects included.

more, those patients presenting with epilepsy were younger and, as demonstrated by the odds ratios, were less likely to have the adverse prognostic factors of focal neurological signs or enhancing lesions on CT scan. In addition, although they were less likely to have radiotherapy they were also less likely to have nonresective surgery. Therefore there are several reasons explaining why these patients have a relatively good prognosis.

The group presenting with epilepsy were divided according to whether or not they had been operated on early. Odds ratios were used to compare the two groups and table 3 shows the relative distribution of clinical and CT features. It is clear that those patients operated on early have the same adverse factors as demonstrated by Cox's model for the whole group and that this is responsible for a bias against the effectiveness of early surgical treat- ment. This selection pattern might easily explain why survival was poorer in the group subjected to early surgery than in the group submitted to either delayed surgery or no surgery.

Cox's stepwise proportional hazards model was used to define the factors influencing outcome in the group presenting with epilepsy. Table 4 demonstrates that outcome is mainly determined by clinical and CT factors. Focal signs at presentation and enhancing lesions on CT scan are associated with a relative risk of mortality of 3.0 and 2.73 respectively. Age at presentation increases the risk of mortality by a factor of 1.2 for every decade. Furthermore, no beneficial treatment effects for either resective surgery or radiotherapy is demonstrated. Table 5 shows the Cox's model for the group whose first symptom was not epilepsy. In marked contrast, outcome in this group appears to be determined mainly by treatment effects with radiotherapy and resective surgery associated with a relative risk or mortality of 0.41 and 0.48 respectively.

\section{Discussion}

These results are derived from a retrospective, non-randomised study and selection bias will have had an important influence on our findings particularly regarding the impact of treatment effects on outcome. For these reasons we cannot claim to have proved anything but rather to have generated a worthwhile hypothesis which demands testing in future studies. It should, however, be noted that this study has considered a heterogeneous group of patients with intracerebra! tumours presenting to both neurologists and neurosurgeons and allows an unusual comparison of the effectiveness of aggressive treatment with the natural history of such lesions.

The principal arguments for the aggressive treatment of tumours presenting with epilepsy are firstly to reduce mortality and secondly to improve control of medically refractory 
seizures. The risks, however, both short and long-term, of surgery and radiotherapy in neurologically intact patients may not be justified if such treatments do not favourably influence the natural history of these lesions.

Our findings support the widely held clinical impression that epilepsy may, for many years, be the only manifestation of intracerebral tumours which behave in a relatively benign manner. Epilepsy as a first symptom appears to be one of the most important ways of identifying tumours with good quality survival. In some studies ${ }^{1116}$ epilepsy has been found to be a favourable prognostic factor only on univariate analysis, being displaced on multivariate analysis by duration of symptoms before diagnosis. ${ }^{11}$ However, these studies have considered only histologically proven malignant gliomas and the number of patients presenting with epilepsy was relatively small. Other workers have found epilepsy as a presenting symptom $^{17}$ and length of history of fits ${ }^{13}$ to be significant independent variables favourably influencing survival.

We have confirmed, in agreement with other studies, the importance of age $\mathrm{e}^{51819}$ and the presence of other symptoms and signs ${ }^{161920}$ at presentation in determining outcome in the group as a whole and the sub-group presenting with epilepsy. Previous reports ${ }^{24}$ on the prognostic significance of contrast enhancement of histologically proven low grade gliomas have been conflicting. In this series enhancement of the lesion on CT scan was the main radiological predictor of outcome in the group as a whole and in those whose first symptom was epilepsy. It should be emphasised that presentation with epilepsy was the second most important variable influencing outcome and that, in addition, such patients were younger and less likely to have other adverse clinical and radiological prognostic factors. We failed to confirm the importance of duration of history before diagnosis ${ }^{172}$ and involvement of the non-dominant hemisphere ${ }^{27}$ as variables influencing outcome.

We did not identify tumour grade as a significant independent variable influencing outcome. This may, however, be partially explained by the absence of histology in 169 / $560(30 \%)$ cases and of those subjected to surgery $139 / 391(35 \%)$ had the diagnosis of tumour confirmed but grade was not specified. In a series of highly malignant tumours ${ }^{1921}$ grade has been shown to influence outcome but in a recent major study ${ }^{13}$ grade was displaced as a significant independent variable by extent of surgical resection. The differing results regarding the influence of tumour grade on outcome may be due to confounding factors including divergence of opinion on grading ${ }^{13}$ and the belief of some pathologists that some tumours with the same Kernohan grade may behave differently in biological terms. ${ }^{28}$

The results derived from this study could be criticised on the basis that only $60-70 \%$ of lesions are histologically proven tumours. More specifically, of the 84 patients in the "no early surgery" group 57 were managed conservatively (that is, no histology obtained) and 27 had delayed surgery. In the latter group the initial decision was to treat conservatively but surgery was subsequently performed and a tumour was confirmed histologically in every case. It could be argued that a significant proportion of those patients, in whom the diagnosis was made on clinical and CT grounds only, did not have gliomas. Of these 57 patients nine have died and 29 others have shown either clinical deterioration, radiological progression of the lesion or both. The diagnosis therefore is dependent on the appearances of the lesion on a single CT scan in only 19 patients. Previous research has demonstrated that a lesion diagnosed as malignant on a single CT scan is subsequently shown to be benign in $1 \cdot 2^{8}-10 \%^{29}$ of cases. Even if this latter figure is applied to our group we feel that there is reasonable doubt about the diagnosis of a tumour in very few cases and that diagnostic error would not explain the observed differences between the groups.

There is good evidence from prospective studies showing the value of post-operative radiotherapy in prolonging survival in malignant glioma. ${ }^{3-5}$ Some workers ${ }^{10-13}$ have found the extent of surgical resection to be associated with improved survival in high grade tumours but this has not always been confirmed. ${ }^{30}{ }^{31}$ In two surgical series extent of resection was found to influence survival in low grade tumours favourably. ${ }^{14} 15$ However, no comparative data regarding untreated tumours is presented in these studies and the potential for selection bias in favour of aggressive treatment has recently been reported. ${ }^{89}$

In this study we failed to demonstrate beneficial treatment effects for either resective surgery or radiotherapy in the group presenting with epilepsy. Conversely in those with other presentations radiotherapy and resective surgery were among the most important factors associated with longer survival. It would therefore appear that in the former group outcome is determined by clinical factors and in the latter group by treatment effects. These findings may be entirely explained by selection bias. In this study it was clear that patients presenting with epilepsy who received early surgery had adverse prognostic factors thus potentially under-emphasising the impact of surgical treatment. Conversely, it has been shown that patients with other presentations are likely to be selected for aggressive treatment if they have favourable features thus overemphasising treatment effects. ${ }^{89}$

We have found that epilepsy due to intracerebral tumours tends to be refractory to antiepileptic drugs with significant remission of seizures being rare. Furthermore, the response of epilepsy to surgical resection was variable with $7 / 23(30 \%)$ of those having early surgery and $5 / 10(50 \%)$ of those undergoing delayed surgery becoming seizure-free-most of these patients had well-circumscribed temporal lobe lesions. Effectiveness of surgical treatment for "tumour epilepsy" has been claimed in some smaller series ${ }^{32} 33$ and the importance of early diagnosis and definitive treatment emphasised. It is likely that these studies are of highly selected groups of patients with well circum- 
scribed lesions and that such information cannot be generalised to less selected populations of tumour epilepsies.

Currently we do not know how best to manage intrinsic supratentorial tumours particularly those with a relatively long natural history. The clinical dilemma is whether patients should be subjected to early treatment with some associated risks and whose benefits we cannot quantify as soon as the diagnosis is made. ${ }^{2}$ This particularly applies to the patient with focal epilepsy, a normal clinical examination and a diffuse, non-enhancing lesion on CT scan. It has been suggested that all such lesions should be biopsied to avoid missing curable conditions and to predict prognosis. ${ }^{2834}$ However, free-hand ${ }^{28}$ and even stereotactic biopsy ${ }^{29}$ are not without risk and histological confirmation of the diagnosis will not necessarily alter management. Although it has been suggested that the risks of resective surgery are less than free-hand biopsy ${ }^{28}$ there is little evidence that this treatment either reduces the risk of mortality or improves the control of epilepsy in the group as a whole. The role of radiotherapy in the management of low-grade glioma has not been established ${ }^{2}$ and the risk of cerebral necrosis ${ }^{35}$ or other complications ${ }^{2}$ in long-term survivors must be considered.

To answer this problem a prospective, randomised, study of aggressive versus conservative management policies is required. This work needs to be performed with some urgency since the increasing availability of sensitive neuro-imaging techniques will lead to an increasing number of patients with focal epilepsy being investigated and found to have such tumours.

1 Wroe SJ, Foy PM, Shaw MDM, et al. Differences between neurological and neurosurgical approaches in the management of malignant brain tumours. BMJ 1986;293 1015-18.

2 Cairncross JG, Laperriere NJ. Low-grade glioma: to treat or not to treat. Arch Neurol 1989;46:1238-9.

3 Anderson AP. Post-operative irradiation of glioblastomas. Results in a randomised series. Acta Radiol 1978;17: 475-84.

4 Kristiansen $\mathrm{K}$, Hagen $\mathrm{S}$, Kollevold $\mathrm{T}$, et al. Combined modality therapy of operated astrocytomas orades 3 and 4 modality therapy of operated astrocytomas grades 3 and 4 lack of potentiation of bleomycin on survival time. Cancer lack of potentiation

5 Walker MD, Green SB, Byar DP, et al. Randomised comparisons of radiotherapy and nitrosoureas for the treatment of malig

6 Gleave JRW. Surgery for primary brain tumours. In: Bleehen NM, ed. Tumours of the brain. Berlin: SpringerVerlag, 1986.

7 Kelly KA, Kirkwood JM, Kapp DS. Glioblastoma multiforme: pathology, natural history and treatment. Cancer Treat Rev 1984;11:1-26.

8 Sandeman DR, Sandeman AP, Buxton P, et al. The man- agement of patients with an intrinsic supratentorial brain tumour. Br J Neurosurg 1990;4:299-312.

9 Winger MJ, MacDonald MD, Schold SC, Cairncross JG. Selection bias in clinical trials of anaplastic glioma. Ann Neurol 1989;26:531-4.

10 Frankel SA, German WJ. Glioblastoma multiforme: review of 219 cases with regard to natural history, pathology, diagnostic method and treatment. $J$ Neurosurg 1958; 15:489-503

11 Winger MJ, MacDonald DR, Cairncross JG. Supratentorial anaplastic gliomas in adults: the prognostic importance of extent of resection and prior low-grade glioma. $J$ Neurosurg 1989;71:487-93.

12 Roth JG, Elvidge AR. Glioblastoma multiforme: a clinical survey. J Neurosurg 1960;17:736-50.

13 MRC Brain Tumour Working Party. Prognostic factors for high-grade malignant glioma: development of a prognostic index. $J$ Neuro-Oncol 1990;9:47-55.

14 Laws ER, Taylor WF, Clifton MB, Okazaki H. Neurosurgical management of low-grade astrocytoma of the cerebral hemispheres. J Neurosurg 1984;61:665-73.

15 Soffietti R, Chio A, Giordana ME, et al. Prognostic factors in well-differentiated cerebral astrocytomas in the adult. well-differentiated cerebral astr.

16 Walker MD, Alexander E, Hunt WE, et al. Evaluation of BCNU and/or radiotherapy in treatment of anaplastic gliomas. $J$ Neurosurg 1978;49:323-43.

17 Scott GM, Gibberd FB. Epilepsy and other factors in the prognosis of gliomas. Acta Neurol Scand 1980;61:227-39.

8 Burger PC, Green SB. Patient age, histological features and length of survival in patients with glioblastoma multiforme. Cancer 1987;59:1617-21.

19 Byar DP, Green SB, Strike T. Prognostic factors for malignant gliomas. In: Walker MD, ed. Oncology of the nervous system. Boston: Martinus-Nijhoff, 1983

20 Gilbert H, Kagan AR, Cassidy F, et al. Glioblastoma multiforme is not a uniform disease. Cancer Clinical Trials 1981;4:87-9.

21 Ammirati M, Galicich JH, Arbit E, Liao Y. Reoperation in the management of malignant glioma. Neurosurgery 1987; the manag

22 Gardner MJ, Altman DG. Estimating with confidence. In: Gardner MJ, Altman DG, eds. Statistics with confidence. London: BMJ, 1989.

23 Tibshirani R. A plain man's guide to the proportional hazards model. Clinical and Investigative Medicine 1982; 5:63-8.

24 Piepmeier JM. Observations on the current treatment of low grade astrocytic tumours of the cerebral hemispheres. $J$ Neurosurg 1987;67:177-81.

25 Silverman C, Marks JE. Prognostic significance of contrast enhancement in low grade astrocytomas of the adult cerebrum. Radiology 1989;139:211-13.

26 Burger PC, Vollmer RT. Histologic factors of prognostic significance in glioblastoma multiforme. Cancer 1980; 46:1179-85.

27 Ohoyama $Y$, Abe $M$, Yabumoto $E$, et al. Radiation therapy in the treatment of glioblastoma. Am J Roentgenol 1986; the trea

28 Walsh ARW, Darling JL, Thomas DGT. Cerebral Gliomas. In: Kennard C, ed. Recent advances in clinical neurology, In: Kennard C, ed. Recent advances in clinical

29 Thomas DGT, Nouby RM. Experience in 300 cases of CTdirected stereotactic surgery for lesion biopsy and aspiration of haematoma. Br J Neurosurg 1989;3:321-6.

30 Hitchcock $E$, Sato $F$. Treatment of malignant gliomata. J Neurosurg 1964;21:497-505.

31 Vecht ChJ, Avezaat CJJ, van Putten WLJ, et al. The influence of extent of surgery on the neurological function and survival in malignant glioma: a retrospective analysis in 243 patients. J Neurol Neurosurg Psychiatry 1990; 53:466-71.

32 Page LK, Lombroso CT, Matson DD. Childhood epilepsy with late detection of cerebral glioma. J Neurosurg 1969; 31:253-61.

33 Lee TKY, Nakasu Y, Jeffree MA, et al. Indolent glioma: a cause of epilepsy. Arch Dis Child 1989;64:1666-71.

34 Choksey MS, Valentine A, Shawdon H, et al. Computed tomography in the diagnosis of malignant brain tumours: tomography in the diagnosis of malignant brain tumours: do all patients require

35 Marks JE, Baglan RJ, Prassad SC, Blank WF. Cerebral necrosis: incidence and risk in relation to dose, time, fractionation and volume. Int J Rad Oncol Biol Phys 1981;7:243-52. 